and rainbow trout generally needed more than any of seven species of coarse fish tested, which is just what anyone would have foretold. Other results are more unexpected; for example, trout survived for a week at a temperature of $20^{\circ} \mathrm{C}$. when the concentration of oxygen was only $29 \cdot 6$ per cent of saturation, and the most exigent species at this temperature was mirror carp, which required 58.9 per cent. Another surprise is the smallness of the difference between the two figures; at $20^{\circ} \mathrm{C}$. the oxygen concentration had only to drop to $28 \cdot 2$ per cent of saturation and no trout survived for a week. There is much in this table for physiologists, ecologists and those charged with the care of fishing waters.

The aerating effect of weirs has been studied, and it has even been possible to find a formula for it.

The rest of the report will interest mainly those directly concerned with pollution problems. An extensive survey of the Thames estuai'y has been made to discover the amount of oxygen that combines with polluting matter and the amount taken by the water from the air, together with the influence of temperature, rate of flow and tidal phenomena on these two processes. The hope was that it might be possible to find general principles from which the effect of the last three on the first two could be predicted. An observer knowing the rate of flow, the temporature, and the state of the tides, which are easily measured, could then say how much polluting matter could be discharged into the stream without causing total oxygen deficiency and nuisance anywhere. The hope has been fulfilled.

Uptake of oxygen is reduced by synthetic deter gents, though the effect diminishes as the concentration of sewage rises. Cetyl alcohol, which is being added to reservoirs in certain parts of the world to see whether it will reduce evaporation, also depresses the rate of oxygen uptake. Substances added to prevent foaming in activated sludge plants do not.

Work on oxygen has been the main preoccupation at the laboratory, experience having shown that the best policy is to keep the field of effort narrow, but much else has been accomplished as well. The toxicity of various substances to fish has been investigated. That of synthetic detergents is reduced by the activated sludge process. Ammonia occurs frequently in polluted waters and, in those charged with sewage, may be the main killing agent beyond the zone where lack of oxygen is acute. Concentrations of 10-15 parts per million $\mathrm{N}$ ammonia affect fish survival considerably. It occurs, too, in effluents resulting from the washing of coke oven gas together with phenol, which is less toxic. The effect of the two substances is complementary, and the toxicity can be calculated when the proportion of the two is known.

When the new Laboratory was boing planned, a site to which large amounts of domestic sewage could be supplied was chosen. Research making use of this facility is following two lines: the elucidation of the fundamental nature of certain processes that aro still largely ornpirical in operation; and methods of treating different kinds of effluent. To the first category belongs a study of the structure of the biological film of a percolating filter and of factors which modify it; the reviewer wonders whether much progress will be made with this until more precise names than 'zooglœeal bacteria', 'nematodes' and 'protozoa' can be given to the organisms in. volved. What exactly happens during the activated sludge process is another thing that the staff intend to find out.

T. T. MACAN

\section{TASTE AND SMELL}

$\mathrm{T}$ HE senses of taste and smell from the physiological and psychological points of view formed the subject of one of the periodical discussion meetings at the Society for Visiting Scientists, London, on May 21. The degree of attention paid during the general discussion to psychological rather than to physiological factors might be held to indicate that, in certain circumstances at least, the scientist was just as interested in his own subjective psychological processes as in the pursuit of objective data. Dr. $H$. Kalmus (University College, London), one of the three opening speakers, began by sketching-in some of the anatomical and physiological background of the receptor organs for taste and smell and then went on to describe some of his own work and that of his associates in this field. Following up the earlier discovery that phenylthiourea tastes bitter to some poople but is apparently tasteless to others, and that this varying power of perception was hereditary, Harris and Kalmus had shown that this simple genetical difference applies, in fact, to a large group of substances containing the CNS group but to no others. In a second line of work, using a series of feeding experiments with two hives of bees and two different food sources, in which use was made of the dancing motions of bees as a method of information transference, Kalmus, together with C. R. Ribbands, had succeeded in confirming von Frisch's discovery that the bees were able to distinguish the taste of bees from their own hive from that of those from the other hive. In this ease, however, the power of distinction was not hereditary. Dr. Kalmus had also worked on the power of odour perception in dogs. He had demonstrated that a dog which had been given the scent of a man's hands could successfully recover a handkerchief scented in the man's armpit from a number of other handkerchiefs scattered about the room, and could trace the man across a field in the open air from the scent left on a handkerchief when the trail was confused by a number of other men. In trials indoors with identical twins the wrong twin might be followed instead of the right one, though in the open air there was some indication that the right twin might be followed in preference. The most interesting point here seemed to be that the dog could recognize a man from his armpit odour (on the handkerchief), having previously been given only the hand odour, whereas to a human being there seemed to be more resemblance between two different armpit odours than between the hand and armpit odours of the same individual. This seemed to indicato a different and perhaps altogether higher power of integration in the dog; Mr. B. Babington Smith used the illuminating analogy of a musician who might rocognize that two sounds apparently different to a non-musical ear were in fact merely octaves of the same note.

Mr. Babington Smith (Institute of Experimental Psychology, Oxford), the second speaker, described some work on non-expert consumer preference panels composed of undergraduates, in which he had been interested rather in the methodology and in the reactions of his subjects than in the actual results of the tests. The tests were confined to simple paired comparisons on red wine and chocolate, though $\mathrm{Mr}$. Babington Smith did not stress the actual results beyond rather mischievously suggesting that there was some indication that the more intelligent people preferred plain to milk chocolate. The incidental 
results were more illuminating. Though consistency was generally aimed at, an individual's reactions, it appeared, were seldom completely consistent and might be based on changing standards as the trial proceeded. The order in which the material was presented might be important, and there was also a problem in the actual quantity of the test material that should be provided. It was possible that the subject might learn about the technique of making comparisons as the test proceeded, and also that an initial preference might turn almost to nausea before the trial was over. Mr. Babington Smith distinguished between 'competitor's' and 'co-operators' among his subjects; the former seemed anxious to find what they felt to be the 'right' answer, whereas the latter did more nearly what they were asked, which was to provide a straightforward description of their reactions. The first type might be useful on expert tasting panels, and the second, who might perhaps be regarded as having the instincts of a gourmet, would be useful in a consumer tasting panel.

Several speakers in the subsequent discussion were not happy about this classification. Mr. Babington Smith indicated that he did not intend a rigid classification into psychological types, his description only applying within the framework of the experiment; he also agreed that there might be a tendency for the less-experienced tasters to be anxious to find the 'right' answer, whereas the more experienced individual was more likely to be relaxed and confident in his appreciations.

The third main speaker, Mr. W. J. Gleeson (Reckitt and Colman, Ltd., Norwich), described a problem on market research for a food manufacturer. This was admittedly in the strict sense an unscientific business, but it was demonstrably possible for consumer surveys of this kind to convey information of which the manufacturer was not aware, and to indicate that the consumer had detected something that the manufacturer had not expected him to notice. The consumer in any event liked to be asked his opinion and would volunteer it even if he was not asked; and so they asked him. One of the principal difficulties in this type of work arose from the fact that the consumer would subsume all the factors affecting his preference, even colour, into the omnibus expression 'flavour'. Other difficulties arose from the necessity to compensate statistically so far as possible for the kind of error-inducing factors which had already been described by Mr. Babington Smith.

During the general discussion, some attention was given to the inevitability, or desirability, according to one's point of view, of using a combination of two or more of the senses in arriving at a subjective judgment of quality. In this connexion, Prof. H. D. Kay (National Institute for Research in Dairying, Shinfield) referred to cheese, Dr. H. J. Strausz (consultant chemist) to essential oils, and Mr. H. J. Bunker (consultant microbiologist) - who started with the story of the small girl who said she could hear the bacon smelling-to beer. Mr. Bunker's work, in contrast to most of the rest, was concerned with expert tasting in pursuit of the maintenance of a standard rather than with consumer preferences. In his field, the powerful assault of hops on the palate provided one of the major difficulties to extended tasting tests. Dr. G. Slot (physician) referred to the deliberate addition of emotional overtones to consumer preference, and instanced his hospital patients, who greatly preferred an expensive but widely advertised glucose drink to his own free prescription for the same material, as well as to those patients who reacted quite differently to red pills and blue pills even when both were aspirin. Mr. R. B. D. Stocker, as a dentist, picked up a reference made by Mr. Gleeson to fashions in taste, and said that in recent years the public taste had changed in a manner inimical to health. Mr. J. M. Harries (Ministry of Agriculture, Fisheries and Food) emphasized that one should not accept a stated preference as valid unless one had previously established the subject's ability to differentiate between the materials on trial, and Dr. Hugh Davson (University College, London) expressed the distaste of a physiologist for experiments in which the subject was asked to express a preference as opposed to those in which he was merely asked if he could tell the difference between two stimuli. Perhaps the last word lay with Dr. Kalmus, who thought that the whole subject would probably remain largely empirical and that it would be a long time before any sweeping, unifying theory emerged.

D. Nevillie-JoNES

\section{USE OF ISOTOPES IN AGRICULTURE}

$T$ HE European Contact Group on the uses of isotopes and radiation in agricultural research has been established by the Food and Agriculture Organization of the United Nations to provide a medium for the exchange of information between European countries on present and planned programmes with the view of identifying applications likely to be of greatest significance for European agriculture. The object is to enable countries to pool their knowledge and experience for the common good and to make most effective use of the facilities available. The first meeting took place at Wageningen, in Holland, during December 10-14, and a report of the proceedings has recently been published*. It was attended by thirty-one representatives of sixteen European member governments and by observers from the United States and the U.S.S.R. and eight international organizations. Dr. S. L. Mansholt, Minister of Agriculture, Fisheries and Food in the Netherlands Government, announced that his Govern. ment had decided to establish an institute at Wageningen for the application of atomic energy in agriculture and as a centre of research, instruction and information. He expressed the hope that this would not remain a purely national institute, but would in due course develop into a European centre for the application of atomic energy in agriculture.

Discussions on the use of isotopes and radiation in agricultural research were organized under five subject headings. The topics concerned with the use of isotopes in soil science included the validity of the isotope technique, determination of active fractions of various soil ions by the isotope-dilution technique, use of labelled fertilizers, vertical migration of soil ions, exchange of ions between roots and medium, and evolution of organic matter in the soil. The delegations described how isotopes are being used in

* Food and Agriculture Organization of the United Nations. European Commission on Agriculture: Sub-Commission on Agricultural Research. Report of the First Meeting of the European Contact Group on the Uses of Isotopes and Radiation in Agricultural Research, held in Wageningen, Netherlands, 10-14 December, 1956. Pp. ii +39 . (Rone
Nations, 1957.) 